those of excessive sexual indulgence and no other." This being so, it follows as a corollary that Dr. West must also believe the physical effects of moderate masturbation to be the same as those of moderate sexual intercourse and no other. Dr. West will not find many converts in the profession to this opinion. For would it be for the welfare of society that such a belief should prerail ; the fear of the injurious $p^{h}$ lskical effects of masturbation has in many instances a most wholesome deterring influence.

Dr. West's third proposition is entirely opposed to the eridence of those who have paid much attention to psychological studies, and who have possessed the advantage of extensire observation among the insane-to wit, Drs. Forbes Winslow, Stillwell, Seaton, Maudsley, Drysdale, Holmes Coote, and others. The latest medical opinions are quite opposed to Dr. West's view. So recently as the 18th of October, in a discussion on a paper read before the Harveian Society, by Dr. Maudsley, "On some of the Causes of Insanity," it was brought out that there was no cause of insanity so common as self-abuse. The late Dr. Helps told me that, of the cases of insanity in the Royal Bethlehem Hospital, in three-fifths of the women and four-fifths of the men the disease was due to masturbation; and I have the evidence of the resident physician of a provincial lunatic asylum to the effect that with the exception of those whose mental aberration was hereditary, and the cases induced by drunkenness, nearly all the rest could be traced to the pernicious habit of masturbation. We cannot say much therefore for Dr. West's faculty of observation, if it be true, as he states, that he has never seen any instance in which hysteria, epilepsy, or insanity in women was due to masturbation. But, if I am correctly informed, Dr. West has had under treatment a lady afficted with hysterical fits of an epileptoid character, which he attributed to masturbation, and for the relief of which he applied caustics to the clitoris without any good results. He then recommended the lady to come to London for the purpose of undergoing the operation of clitoridectomy. Further, in another case brought to me by an eminent physician in London, Dr. West had given his opinion to the effect that that case was a suitable one for my operation. How do these facts accord with Dr. West's statement in his third proposition?

In his fourth proposition Dr. West states that of the alleged cures of hysteria \&c. by excision of the clitoris, a very large number were not permanent. Does Dr. West admit that any of the alleged cures have been permanent? If so, he must allow the operation to take its place as one of the remedies, amongst others, for the relief of a most intractable class of diseases. But more permanent cures have followed the operation than Dr. West is inclined to admit, or is probably aware of. I never insisted that it was an unfailing remedy in every case, but I do insist that in suitable cases it has a marvellously beneficial influence on the whole nervous system of the patient operated on.

Dr. West's fifth proposition deals with the moral aspect of the question. He reasonably rejects the idea of medicine or surgery having the power to remove from a mind its impurity. I have never advanced such an opinion. I cannot allow the operation of clitoridectomy to be considered as other than a means of curing a morbid physical condition. On this mental improvement generally follows. Having seen a very large number of cases, I have come to the conclusion that, in a very great proportion, the irritation, and the effort of the patient to relieve that irritation by friction, are, in their origin, quite unconnected, and have nothing whatever to do with impurity of mind. We have no right to attribute immorality to the victims of a habit which often commenced in childhood, and which was then purely physical in its origination.

The sixth proposition contains Dr. West's opinion upon the physiological correctness of the operation of clitoridectomy. All I have to say on this point is that our greatest authorities in physiology, and among them Dr. Brown-Séquard, attribute epileptic fits tc peripheral irritation. Then as to the results which do or do not warrant the frequent performance of the operation. If Dr. West thinks the operation may be performed at all, as is the inference, what becomes of his physiology? But, practically, one fact is worth a dozen iheories, so I will here quote from a letter I have received from $\mathrm{Mr}$. Smith, surgeon, Clare, Suffolk, dated the 15th inst. I quote verbatim :- "My patient, Miss B__-, having now been with me over six months, I think $I$ am in some measure enabled to give my opinion in regard to the operation of clitoridectomy. Much has been said and written pro and con. on this operation, but in my humble opinion I am persuaded but for your operation Miss B- would have been in an asylum long ere this.
When she came to me she was suffering from all the symptoms of hysterical mania. Now she is calm and quiet, associates with the rest of the family, and in fact is a reasonable being; this I consider she orres mainly to you. I feel bound to offer this tribute to your skill, as I know many in the profession com. pletely ignore the benefits resulting from your operation."

I am at a loss to know what Dr. West's serenth proposition aims at. My book " On the Curability of Certain Forms of Insanity, Epilepsy, Hysteria," \&c., is written for the profession solely, and from its technicality could not, I believe, be understood by " non-medical persons."

Dr. West's eighth proposition I entirely agree with as applied to children and persons under age. But in the case of women of mature age, married or unmarried, I have yet to learn that an operation may not be performed, if thought necessary, for the well-being of the patient without consulting her friends if it be her expressed wish that it should be kept secret.

Unwillingness to occupy more of your space prevents me from quoting the testimonies of undoubted authorities as to the value of the operation and the excellent results which follow, but I am willing and anxious to do so if you can spare me the space.

In conclusion, I cannot help remarking that in the first edition of his treatise on the Diseases of Women, Dr. West devoted an article to prove how unscientific was my operation for prolapsus uteri, an operation which is now adopted by the first surgeons in every civilised country.

I have well-grounded hope that the same result will follow his opposition to the present procedure for the relief of a still more distressing class of ailments.

Harley-street, Nov. 1866

I am, Sir, your obedient servant,

\section{FEVER HOSPITAL IN THE EAST OF LONDON.} To the Editor of THE LANCET.

SIR, - The following copy of a letter is in the course of signature. If you will kindly publish it in your extensively read periodical, you will oblige,

Your humble servant,

Campbell-terrace, Bow-road, Nor. 24th, 1866. JOHN LIDDLE.

To the Committee of the Temporary Cholera Hospital in Commercial-street, Spitalfields.

Ladies AND Gentuemen,-We, the undersigned medical officers of the Unions in the Eastern districts of London, having learned that it is the desire of some benevolent persons to erect an hospital for the relief of the poor suffering from fever and other epidemic diseases, believe that such an institution will be of incalculable benefit to the poor of these districts.

From the practical knowledge we have acquired from our extensive practice among the poor, we can confidently state that fever and other epidemic diseases prevail to a very great extent in these localities, on account of the density of the population and the unhealthiness of the dwellings.

It is truly lamentable that London, with its $3,000,000$ inhabitants, has only one Fever Hospital and one Small-pox Hospital, and both are situated at a great distance from these centres of disease. It therefore happens that many patients cannot be removed to these establishments in consequence of the frequent want of room in them, and from the danger attendant upon the removal of the sick to such a distance from their abodes. They are therefore suffered to remain in their miserable habitations, thereby exposing their families and fellow-lodgers to the danger of infection. Hence the urgent necessity for an institution, to meet the worst of this class of patients, being erected within a reasonable distance of these districts, so that patients might be removed more promptly and safely than can now be accomplished.

\section{ACTION OF THE MUSCULAR COAT OF THE URETHRA. \\ To the Editor of THE LAXCET.}

Sir,-Will you kindly allow me a small space in your journal to make a few remarks on the subject of urethral morements seen through the endoscope? I think it has been too soon taken for granted that a foreign body in the urethra will be propelled by the vermicular wares in the same direction in which they themselves are moving. Now, I think it 